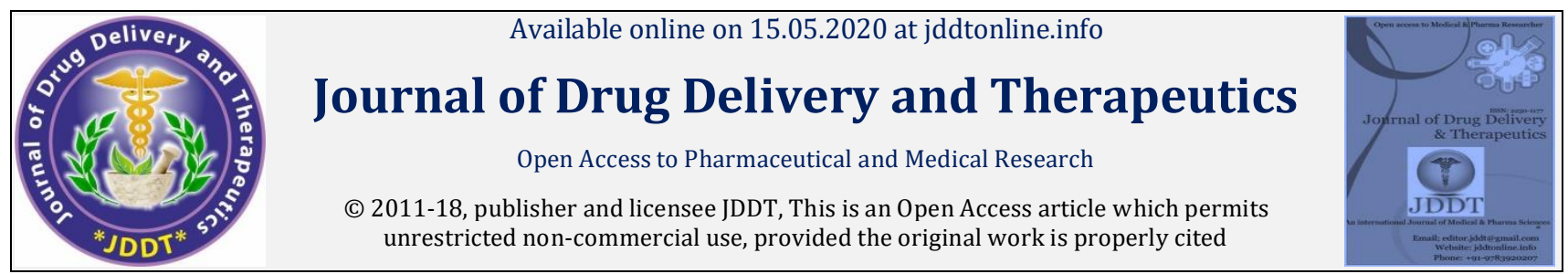

Open 2 Access

Research Article

\title{
Psychological and Anxiety/Depression Level Assessment among Quarantine People during Covid19 Outbreak
}

\author{
Kushagra Sharma *, Joseph Saji , Ranjeet Kumar , Abins Raju \\ Department of Pharmacy Practice, NIMS University Rajasthan, Jaipur, India
}

\begin{abstract}
Background- Covid-19 outbreak results in lockdown of provinces by isolating the infected ones and quarantine the population to prevent community spread of corona virus. During quarantine people has to restrict their movement and keep themselves under self-isolation at their home to prevent infections. In long quarantine period it may create psychological or anxiety/depression problem for some people. The objective of our study is to assess and understand the level of psychological, anxiety/depression in quarantine people during covid19 outbreak.

Methods- Self-designed digital questionnaire has been used to assess the psychological and anxiety/depression level. The questionnaire contains questions about demographic, socio-assessment, anxiety/depression and psychological assessment. The questionnaire was circulated via digital medium.

Result- Total 181 quarantined people were participated in our study, most of our population ages between of 21-30. General health of our participants is moderately good, Socio-status of our participants is fairly effected may be due to restrict movement and conservative way of living during quarantine period. $60.8 \%$ of participants become nervous some of the time, about $50 \%$ of participants shows the anxiety/depression symptoms, about 30\% of our participants are somewhat affected by their sleeping patterns and about 35\% participants are sometimes unsatisfied or slightly satisfied during quarantine period. Apart from this out of 181 participants 15 people are having travel history of International or national destinations. The overall mean is 2.2 and SD is 0.6 .
\end{abstract}

Conclusion-We found somewhat negative emotions (anxiety/depression, Socio status) in people during quarantine. Which may show low quality of life or low satisfactory life.

Keywords: Covid-19, lockdown, quarantine, anxiety, depression

Article Info: Received 21 March 2020; Review Completed 29 April 2020; Accepted 06 May 2020; Available online 15 May 2020

Cite this article as:

Sharma K, Saji J, Kumar R, Raju A, Psychological and Anxiety/Depression Level Assessment among Quarantine People during Covid19 Outbreak, Journal of Drug Delivery and Therapeutics. 2020; 10(3):198-201

http://dx.doi.org/10.22270/jddt.v10i3.4103

*Address for Correspondence:

Kushagra Sharma, Department of Pharmacy Practice, NIMS University Rajasthan, Jaipur, India

\section{INTRODUCTION}

According to World Health Organization, novel Coronavirus (Covid19) belongs from virus family which is responsible for common cold to uncommon severe respiratory conditions like Severe acute respiratory syndrome (SARS-CoV) and Middle east respiratory syndrome (MERS-CoV). These types of viruses are zoonotic which can infect human or any other wild animal via respiratory, gastrointestinal, as well as central nervous system ${ }^{1-3}$. SARS-CoV transmitted from cat to humans and MERS-CoV transmitted from dromedary camel to humans 4 . Since late 2019, first mysterious pneumonia case found in the Chinese city (Wuhan) drawn an attention around the world. After the numerous studies researchers and Chinese government found that causative agent of this mysterious pneumonia is novel coronavirus (Covid19). International Committee of Taxonomy of Viruses (ICTV) defines Covid19 as severe global health threat and it should unavoidable because of climatic, ecologic and high humans and animals' interaction factors ${ }^{5}$. The only way to minimal interaction between people is quarantine. Quarantine is a separation or restriction of movement of people who are exposed or at risk of infectious disease ${ }^{6}$. It is first used in Italy in 1127 in regards of leprosy. Quarantine has been used since centuries to control and prevent infectious diseases like cholera, plaque, Black Death, SARS, MERS, etc 7-13. Quarantine separates the exposed persons to general or healthier community. It may create psychological or anxiety/depression problem for some people. The objective of our study is to assess and understand the level of psychological, anxiety/depression in quarantine people during covid19 outbreak. 


\section{METHODOLOGY}

This study was carried out in general community. The data was collected from the quarantine people by fulfilling the inclusion criteria taken under the study who were quarantine by the government authorities or from both those who having or not having travel history. A suitable questionnaire form will design to collect and document the data by using Google Doc. Questionnaire form includes questions about demographic details, Socio-status, anxiety/depression level and psychological level assessment. Questionnaire data were analysed by using Google Doc.

\section{RESULT}

Self-designed suitable questionnaire has been used to assess the level of psychological or anxiety/depression in quarantine people. Questionnaire includes demographic Questions, socio-status, anxiety/depression and psychological assessment. Total 181 people were participated in this study from which 102 (56.4\%) were females and $79(43.6 \%)$ were males.

Table 1: Age group and Gender

\begin{tabular}{cccc}
\hline Age groups & No. of Males & No. of Females & Total \\
\hline Below 20 & 10 & 19 & 29 \\
\hline $21-30$ & 57 & 76 & 133 \\
\hline $31-40$ & 04 & 04 & 8 \\
\hline $41-50$ & 02 & 04 & 6 \\
\hline $51-60$ & 03 & 01 & 4 \\
\hline Above 60 & 00 & 01 & 1 \\
\hline
\end{tabular}

Out of 181 people, 53 (29.3\%), 99 (54.7\%), 27 (14.9\%), 2 (1.1\%) people felt that their general health is excellent, good, fair and poor respectively. The mean is 3.1 and SD is 0.6.

Table 2: General Health

\begin{tabular}{llllll} 
Excellent & Good & Fair & Poor & Mean & SD \\
\hline $53(29.3 \%)$ & $99(54.7 \%)$ & $27(14.9 \%)$ & $2(1.1 \%)$ & 3.1 & 0.6 \\
\hline
\end{tabular}

Out of 181 people, $9(5 \%)$ people were think that their emotional problems are severely effects their social activities, 44 $(24.3 \%)$ people were moderately effected, $78(43.1 \%)$ people were fairly effected and $50(27.6 \%)$ people were think that their emotional problems are not effects their social activities during quarantine period. The mean is 2.9 and SD is 0.8 .

Table 3: Socio Status

\begin{tabular}{llllll}
\hline Severely effected & Moderately effected & Fairly effected & Not effected & Mean & SD \\
\hline $9(5 \%)$ & $44(24.3 \%)$ & $78(43.1 \%)$ & $50(27.6 \%)$ & 2.9 & 0.8 \\
\hline
\end{tabular}

Out of 181 people, $1(0.6 \%)$ person feel nervous during quarantine period. $16(8.8 \%)$ people feels most of the time, $110(60.8 \%)$ people feels some of the time and 54 (29.8\%) people not feeling nervous during quarantine period. The mean is 3.1 and SD is 0.6 .

Table 4: Nervousness status

\begin{tabular}{llllll}
\hline All of the time & Most of the time & Some of the time & Not at all & Mean & SD \\
\hline $1(0.6 \%)$ & $16(8.8 \%)$ & $110(60.8 \%)$ & $54(29.8 \%)$ & 3.1 & 0.6 \\
\hline
\end{tabular}

Out of 181 people, $5(2.8 \%)$ people felt anxiety/depression all of the time during quarantine, 12 (6.6\%) people felt anxiety/depression most of the time, $91(50.3 \%)$ people felt some times anxiety/depression and $73(40.3 \%)$ people not felt any sign of anxiety/depression during quarantine period. The mean is 2.8 and SD is 0.9 .

Table 5: Anxiety/Depression status

\begin{tabular}{llllll}
\hline All of the time & Most of the time & Some of the time & Not at all & Mean & SD \\
\hline $5(2.8 \%)$ & $12(6.6 \%)$ & $91(50.3 \%)$ & $73(40.3 \%)$ & 2.8 & 0.9 \\
\hline
\end{tabular}

Out of 181 people, $29(16 \%)$ people are unsatisfied with their sleeping pattern, $29(16 \%)$ people are slightly satisfied, 65 $(35.9 \%)$ people were satisfied, and $58(32 \%)$ people were very satisfied with their sleeping pattern during quarantine period. The mean is 2.6 and SD is 1.1. 
Table 6: Sleeping Pattern

\begin{tabular}{llllll}
\hline Unsatisfied & Slightly Satisfied & Satisfied & Very Satisfied & Mean & SD \\
\hline $29(16 \%)$ & $29(16 \%)$ & $65(35.9 \%)$ & $58(32 \%)$ & 2.6 & 1.1 \\
\hline
\end{tabular}

Out of 181 people, $21(11.6 \%)$ people are unsatisfied with their ability to perform daily living activities, 42 (23.2\%) people were slightly satisfied, 90 (49.7\%) people were satisfied and $28(15.5 \%)$ were very satisfied with their ability to do daily living activities during quarantine period. The mean is 2.4 and SD is 0.8 .

Table 7: Ability to perform daily activities

\begin{tabular}{llllll}
\hline Unsatisfied & Slightly Satisfied & Satisfied & Very Satisfied & Mean & SD \\
\hline $21(11.6 \%)$ & $42(23.2 \%)$ & $90(49.7 \%)$ & $28(15.5 \%)$ & 2.4 & 0.8 \\
\hline
\end{tabular}

Out of 181 people, $4(2.2 \%)$ people are unsatisfied with their access to health service, $39(21.5 \%)$ people are slightly satisfied, $101(55.8 \%)$ people are satisfied and $37(20.4 \%)$ people are very satisfied with their access to health service during quarantine period. The mean is 2.6 and SD is 0.8 .

Table 8: Access to health service

\begin{tabular}{llllll}
\hline Unsatisfied & Slightly Satisfied & Satisfied & Very Satisfied & Mean & SD \\
\hline $04(2.2 \%)$ & $39(21.5 \%)$ & $101(55.8 \%)$ & $37(20.4 \%)$ & 2.6 & 0.8 \\
\hline
\end{tabular}

Out of 181 people, 5 (2.8\%) people were feel unsafe during quarantine life, 18 (9.9\%) people were feel slightly safe, 90 (49.7\%) people were feel safe and $68(37.6 \%)$ people were feel very safe during quarantine life. The mean is 3.2 and SD is 0.7 .

Table 9: Safety during quarantine

\begin{tabular}{llllll}
\hline Unsafe & Slightly Safe & Safe & Very Safe & Mean & SD \\
\hline $5(2.8 \%)$ & $18(9.9 \%)$ & $90(49.7 \%)$ & $68(37.6 \%)$ & 3.2 & 0.7 \\
\hline
\end{tabular}

Out of 181 people, $15(8.3 \%)$ people having travel history of International or national destinations with direct exposure of Covid-19 outbreak hotspot areas. The overall mean is 2.2 and SD is 0.6.

\section{DISCUSSION}

In relation to the recent outbreak of Covid-19, world's population placed in quarantine to restrict the community spread of transmissible disease. According to BIS, people should behave in a conservative way when they feel threatened by disease ${ }^{14}$. By staying at home with family and exploit by doing new activities seems to be a safer way to prevent psychological symptoms or loneliness. People should begin care more about their health while staying at home rather than getting together with friends or community. Restricted travel policy and self-isolation regulations from the health authorities and state/central governments are for people' safety and to restrict community spread. As various reports showed severity and mortality of Covid-19. The motive of our study is to understand the needs and concerns of quarantined people. To our knowledge, a consideration of the adverse effects of quarantine due to Covid-19, including psychological effects, has not previously been systematically attempted. Our result shows that the persons in quarantine are stressed and shows the symptoms of anxiety/depression among them. About half of the population admitted the symptoms of anxiety/depression some of the time during their quarantine period. Similar, results are showed in previous studies during SARS, where high level of anxiety/depression level were recorded 15,16. Furthermore, socio status of quarantined people were also somewhere effected. As this outbreak bring them to the risk of quick judgment and perception as per risk theory showed 17 . Government's policies and regulations of self-isolation and travel made people' Quality of life slightly unsatisfied as their ability to perform daily living activities are effected during quarantine period.

Points should be considered when generalizing this study finding:

- Quarantined people in our study are mainly young people (21-30), the results may be biased to some extent.

- Our result may influence by changing trends of mentality of person to person in a timely manner.

\section{CONCLUSION}

In this study, we analyse the psychological or anxiety/depression level or behaviour of quarantined people during Covid-19 outbreak. We found somewhat negative emotions (anxiety/depression, Socio status) in people during quarantine. Which may show low quality of life or low satisfactory life. Although, social distancing plays an important role to prevent community spread of virus among the countries. Governments should aware for mental health of people and should conduct studies (similar to this) among quarantine people and show them various ways to prevent mental conditions in quarantine people.

\section{ACKNOWLEDGMENT}

We express our deepest gratitude to Dr. Vishnu R Nair for all his support and optimistic encouragement. We would also like to express our sincere gratitude to our family members 
who ingrained us with all the necessary values and ambition to successfully complete this study. Above all are eternally thankful to GOD almighty for his blessings on us as well as those around us throughout the study.

\section{REFRENCES}

1. Wang, L.F., et al., Review of bats and SARS. Emerg Infect Dis, 2006. 12(12): p. 1834-40.

2. Ge, X.Y., et al., Isolation and characterization of a bat SARS-like coronavirus that uses the ACE2 receptor. Nature, 2013; 503(7477):535-8.

3. Chen, Y. and D. Guo, Molecular mechanisms of coronavirus RNA capping and methylation. Virol Sin, 2016; 31(1):3-11.

4. World Health Organization: https://www.who.int/healthtopics/coronavirus

5. Chen Y., Liu Q., Guo D. et al., Coronaviruses: genome structure, replication, and pathogenesis. doi: 10.1002/jmv.25681.

6. Centers for Disease Control and Prevention. Quarantine and isolation. 2017. https://www.cdc.gov/quarantine/index.htm (accessed Jan 30, 2020).

7. Risse GB. "A long pull, a strong pull and all together": San Francisco and bubonic plague, 1907-1908. Bull Hist Med. 1992; 66:260-86.

8. Twu SJ, Chen TJ, Chen CJ, Olsen SJ, Lee LT, Fisk T, et al. Control measures for severe acute respiratory syndrome (SARS) in Taiwan. Emerg Infect Dis. 2003; 9:718-20.

9. Centers for Disease Control and Prevention. Update: use of quarantine to prevent transmission of severe acute respiratory syndrome- Taiwan 2003. MMWR Morb Mortal Wkly Rep. 2003; 52:680-3.

10. Mandavilli A. SARS epidemic unmasks age-old quarantine conundrum. Nat Med. 2003; 9:487.

11. Barbera J, Macintyre A, Gostin L, Inglesby T, O’Toole T, DeAtley $\mathrm{C}$, et al. Large-scale quarantine following biological terrorism in the United States: scientific examination, logistic and legal limits, and possible consequences. JAMA. 2001; 286:2711-7.

12. Markel H. Knocking out the cholera: cholera, class and quarantines in New York City, 1892. Bull Hist Med. 1995; 69:420-57. 8.

13. Markel H. Cholera, quarantines and immigration restriction: the view from John Hopkins, 1892. Bull Hist Med. 1993; 67:691-5.

14. Schaller, M.; Park, J.H.; Kenrick, D.T. Human evolution and social cognition. In Oxford Handbook of Evolutionary Psychology; Dunbar, R.I.M., Barrett, L., Eds.; Oxford University: Oxford, UK, 2007; pp. 491-504.

15. Maunder, R.; Hunter, J.; Vincent, L.; Bennett, J.; Mazzulli, T. The immediate psychological and occupational impact of the 2003 SARS outbreak in a teaching hospital. Can. Med Assoc. J. 2003; 168:1245-1251.

16. Tam, C.W.C.; Pang, E.P.F.; Lam, L.C.W.; Chiu, H.F.K. Severe acute respiratory syndrome (SARS) in Hong Kong in 2003: Stress and psychological impact among frontline healthcare workers. Psychol. Med. 2004; 34:1197-1204.

17. Slovic, P. Perception of risk. Science 1987; 236:280-285. 